\section{Estudo \\ CoDebate}

em Testão

Planejamento
Revista Estudo \& Debate, Lajeado, v. 25, n. 3, 2018. ISSN 1983-036X

DOI: http://dx.doi.org/10.22410/issn.1983-036X.v25i3a2018.1628

\title{
IMPACTOS REGIONAIS ASSIMÉTRICOS DA POLÍTICA CAMBIAL SOBRE A ARRECADAÇÁO DO ICMS NO BRASIL: UMA ABORDAGEM COM O MÉTODO VAR
}

\author{
Jacó Braatz ${ }^{1}$, Rodrigo da Rocha Gonçalves ${ }^{2}$
}

\begin{abstract}
Resumo: A política cambial e seus efeitos assimétricos para o Brasil são avaliados neste artigo. Com o objetivo principal de avaliar como a arrecadaçáo do ICMS - Imposto sobre a Circulação de Mercadorias e Serviços de cada estado da federaçáo é afetada pelas variaçóes no nível de câmbio. Utilizou-se a modelagem de Vetores Auto-Regressivos (VAR) para dados entre 1997 e 2015, disponíveis para os 27 estados brasileiros, buscando quantificar o efeito que essa mudança trará para a arrecadação de ICMS dos diversos estados do país, a intensidade e a repercussão desses efeitos e as possíveis causas desses potenciais efeitos assimétricos. Os resultados demonstram que há assimetrias nas respostas das economias regionais em resposta a choques nacionais que são constatados impactos regionalmente diferenciados na amostra utilizada. Estrutura produtiva, inserção no comércio internacional e diversidade econômica são características que poderiam explicar os diferentes níveis de impactos, com diferenças bastante acentuadas na intensidade e temporariedade das respostas.
\end{abstract}

Palavras-chave: Política cambial. Impactos regionais. ICMS.

Classificaçáo JEL: C32; E17; R11.

\section{REGIONALS ASYMMETRICS IMPACTS OF EXCHANGE RATE POLICY ON THE COLLECTION OF ICMS IN BRAZIL: AN APPROACH WITH THE VAR METHOD}

\begin{abstract}
The exchange rate policy and its asymmetric effects for Brazil are evaluated in this paper. With the objective of analyzing how the collection of the ICMS - Tax on the Circulation of Goods and Services - of each state of the federation is affected by the variations in the exchange rate. We used the Auto-Regressive Vector modeling was used for data between 1997 and 2015, available for the 27 Brazilian states, seeking to quantify the effect that this change will bring to the collection of ICMS from the different states of the country, what the
\end{abstract}

1 Doutorando em Economia pelo Programa de Pós-Graduação em Economia da Pontifícia Universidade Católica do Rio Grande do Sul - PPGE/PUCRS e Auditor Fiscal da Receita Estadual do Rio Grande do Sul. E-mail: jacobraatz@hotmail.com.

2 Doutorando em Economia pelo Programa de Pós-Graduação em Economia da Pontifícia Universidade Católica do Rio Grande do Sul - PPGE/PUCRS e professor da Universidade Federal de Rio GrandeFURG. E-mail: rrochagoncalves@gmail.com. 
intensity and the repercussion of these effects and the what are the possible causes of these potential asymmetric effects. The results show that there are asymmetric effects on the responses of the regional economies in response to national shocks, that is, regional differences are detected in the sample used. Productive structure, insertion in international trade and economic diversity are characteristics that could explain the different levels of impacts, with marked differences in the intensity and timeliness of responses.

Keywords: Exchange rate policy. Regional impacts. ICMS.

JEL Classification: C32; E17; R11.

\section{Introduçáo}

O setor público no Brasil enfrenta uma grave crise fiscal, principalmente nos âmbitos federal e estadual, a qual limita o planejamento de políticas públicas e a manutenção de serviços essenciais à sociedade no médio e longo prazo, tais como, saúde, educação, segurança, justiça e defesa nacional. Dessa forma, depara-se com um dilema entre a incapacidade de extrair recursos via arrecadação e rigidez de gastos imposta pela demanda crescente de serviços públicos e a baixa eficiência na execução das despesas.

No caso dos estados, os gastos com pessoal e encargos sociais representam aproximadamente $55 \%$ das suas despesas totais, segundo dados do Tesouro Nacional (2016). Os gastos com folha de pagamentos dos ativos e inativos, além dos encargos sociais, comprometem uma grande parcela das despesas correntes. Na concepção da Secretaria de Política Econômica do ministério da fazenda (SPE, 2015), a elevada rigidez orçamentária gerada pelo crescimento das despesas obrigatórias reduz a capacidade do governo de fazer adequaçóes dos gastos públicos, tornando-se necessária uma reforma fiscal que busque reduzir as despesas correntes e a redução da rigidez orçamentária.

Por outro lado, conforme dados do Tesouro Nacional (2016), a arrecadação de tributos dos estados contraiu-se nos últimos anos e não acompanhou o aumento das despesas, gerando um desiquilíbrio fiscal em alguns desses, tais como, Rio Grande do Sul, Minas Gerais, Rio de Janeiro, Alagoas e São Paulo, os quais apresentam uma relação Dívida Consolidada Líquida/Receita Corrente Líquida acima do que é permitido em lei.

Por isso, entende-se a necessidade de quantificaçáo dos fatores que afetam a arrecadação de tributos dos estados, principalmente efeitos assimétricos de políticas econômicas uniformes no âmbito nacional. Bonelli (2005) menciona que mudanças na política macroeconômica nacional afetam todas as regiôes, porém o desempenho econômico dessas regióes se diferencia por fatores como: estruturas produtivas locais; formas de inserção e estratégias de penetração de mercados internacionais das empresas ali localizadas; características da demanda dos setores em que se inserem; comportamento macroeconômico e política comercial dos países destino das exportaçôes e eficiência produtiva local.

Na mesma linha, Myrdal (1968) entende que o crescimento econômico como um processo, essencialmente divergente e concentrador, pode levar a desequilíbrios regionais e assimetrias entre as regióes de um mesmo país. Por outro lado, Boisier (1989) menciona que as políticas macroeconômicas são consideradas regionalmente neutras, ou seja, com impactos regionais uniformes. 
Nesse sentido, o presente artigo, procurar-se-á abordar a política cambial e seus potenciais efeitos assimétricos regionais sobre a arrecadação do Imposto sobre a Circulação de Mercadorias e Serviços (ICMS), ou seja, dada uma modificação exógena no nível de câmbio, qual o efeito que essa mudança trará para a arrecadação de ICMS dos diversos estados do país. Aprofundando o estudo, por quanto tempo as economias estaduais são afetadas? Qual a intensidade e a repercussão desses efeitos? Quais são as possíveis causas desses potenciais efeitos assimétricos?

Assim, a hipótese central a ser estudada é a de que variações uniformes na taxa de câmbio nacional têm efeitos assimétricos, distintos sobre a arrecadação de cada unidade da federação, dependendo da sua estrutura produtiva e de sua inserção no comércio internacional. Especificamente, será testada a hipótese de que uma variação na taxa de câmbio produz efeitos diferenciados sobre a variável "arrecadação de ICMS", entre os estados, através do uso da metodologia VAR. Essa metodologia foi escolhida por permitir avaliar o impacto dinâmico das perturbações aleatórias sobre o sistema de variáveis, o que a torna particularmente útil e eficiente na previsão do comportamento futuro de séries temporais inter-relacionadas.

$\mathrm{O}$ artigo divide-se em quatro seções, além desta introdução e das consideraçôes finais. Na segunda seção, se discute o referencial teórico, com a apresentação de análises que buscam explicar os efeitos assimétricos das políticas macroeconômicas sobre as estruturas produtivas locais e sobre as distintas regióes de um país; na terceira, apresenta-se o perfil de arrecadação de ICMS por partes dos estados. Na quarta seção, é abordada a modelagem de estudo e os procedimentos tomados para se chegar aos resultados; na quinta seção, são apresentados os resultados do trabalho, com as estimaçóes do modelo, a análise das funçóes impulso-resposta (FIR) e os efeitos dinâmicos dos choques cambiais sobre as variáveis objeto de estudo.

\section{Efeitos Regionais da Política Econômica}

A literatura econômica empírica que aborda efeitos regionais de políticas econômicas é extensa, sendo assim, torna-se importante o detalhamento dos principais trabalhos, buscando entender as políticas analisadas e os principais resultados encontrados, faz-se uma síntese da literatura sobre efeitos assimétricos de políticas econômicas a seguir.

Eichengreen (1991) analisou a mobilidade do trabalho e a incidência de choques ocorridos na Europa, comparando-os com medidas desse tipo no Canadá e nos Estados Unidos. Os resultados indicaram que taxas de câmbio reais, uma medida padrão da extensão de distúrbios assimétricos e preços reais de títulos e uma medida de incentivo para realocar o capital produtivo pelas regióes, permanecem consideravelmente mais variáveis na Europa do que nos Estados Unidos. A mobilidade do trabalho e a velocidade de ajuste do mercado permanecem mais baixos na Europa do que nos Estados Unidos.

Wyplosz (2002) estudou se a união monetária é realmente um objetivo desejável, pelo menos a nível regional no longo prazo. Os resultados demonstram que choques assimétricos de curto prazo trazem variabilidade devido a diferentes estágios e velocidades de desenvolvimento de seus países-membros. Tais choques exigem ajustes regionais de 
preços e salários, levantando duas questóes principais: primeiro, mercados de bens e de trabalho precisam exibir a flexibilidade necessária para permitir que esses ajustes ocorram, sem grandes distúrbios macroeconômicos; segundo, a convergência real tem uma grande importância. Quanto maior a diferença na estrutura produtiva dos membros da uniâo monetária, maior será a necessidade de alteraçóes de preços.

Ramos et al. (2001) verificam as implicaçóes macroeconômicas em nível regional da União Monetária Europeia. Na concepção dos autores, choques assimétricos não podem ser tratados por uma política monetária comum, outros mecanismos de ajuste são necessários para alcançar a estabilização macroeconômica. Além disso, as evidências têm mostrado que os países europeus têm uma capacidade de resposta mais baixa do que outras áreas monetárias, e, além disso, as regióes não são igualmente afetadas pelo problema de choques assimétricos.

Kouparitsas (2001) avaliou se os Estados Unidos é uma área monetária ótima como proposto por Mundell. Os resultados indicam que a importância relativa de choques comuns difere um pouco entre as regióes. No entanto, a principal influência sobre a atividade regional parece ser um choque comum na renda que não é explicada por choques para o preço relativo da política de óleo ou monetária.

Haddad et al. (2001) estudam os efeitos regionais das políticas comerciais para os 27 estados da federação, levando em consideração o comércio internacional de cada estado. Segundo os autores, a contribuição depende da natureza do setor de exportação e da distribuição do seus benefícios e as ligaçóes do setor com o resto da economia. Dessa forma, as estratégias de integração examinadas podem aumentar a desigualdade regional no país, elevando a concetração industrial nas regiōes mais desenvolvidas, ou seja, constata-se efeitos regionais assimétricos.

Kume e Piani (1998) mensuraram os efeitos regionais para os estados brasileiros da criaçáo do Mercosul. Os resultados demonstraram que os estados mais favorecidos com a criação do bloco foram: Bahia, Rio de Janeiro, São Paulo e Rio Grande do Sul, mostrando a importância desse mercado externo para essas economias regionais. Em relação às importaçóes, os mais afetados foram Pernambuco, Paraná, Rio de Janeiro, Santa Catarina e Rio Grande do Sul, o que denota um elevado grau de competição da produção desses estados com as importaçóes do bloco.

Braatz e Moraes (2016) verificaram os efeitos da política monetária e seus potenciais efeitos assimétricos regionais nos estados brasileiros. Os resultados indicaram assimetrias nas respostas dos estados brasileiros frente a choques macroeconômico, já que foram constatados impactos regionalmente diferenciados na amostra utilizada, comprovando que características como estrutura produtiva e inserção no comércio internacional das economias regionais são de suma importância para explicar os diferentes níveis de impactos, com diferenças. Além disso, os resultados mostraram que os estados ao sul foram menos afetados que os estados ao norte pela política monetária.

Por sua vez, Braatz e Moraes (2016) analisaram os efeitos da política cambial sobre os estados brasileiros e seus potenciais efeitos assimétricos regionais. $\mathrm{O}$ trabalho também confirmou a existência de assimetrias nas respostas dos estados brasileiros frente a choques 
macroeconômicos comuns, demonstrando que características econômicas são vitais para explicar esses efeitos. Sendo os estados das regióes Norte, Nordeste e Centro-Oeste mais afetados que os demais.

A síntese da literatura empírica sobre efeitos regionais assimétricos de políticas econômicas realizada anteriormente, indica que a maior parte dos trabalhos analisa políticas comerciais e monetárias, predominando como metodologia adotada os modelos econométricos de séries temporais. Porém, constata-se uma carência de trabalhos que avaliam efeitos de políticas econômicas sobre a arrecadação de tributos.

Por isso, a contribuiçẫo deste artigo é avaliar os efeitos regionais assimétricos da arrecadação de ICMS dos estados produzidos pela variação comum na taxa de câmbio da economia utilizando-se a metodologia VAR.

\section{Perfil de arrecadaçáo de ICMS dos Estados Brasileiros}

Os estados brasileiros enfrentam problemas de desequilíbrios fiscais, principalmente no que tange ao pagamento da divida pública, elevação dos gastos com pessoal e a redução da arrecadação de impostos. Dentro desse contexto, a arrecadação do ICMS torna-se fundamental para um ajuste fiscal, pois representa em torno de $80 \%$ da arrecadação total de tributos dos estados, conforme dados do Conselho Nacional de Política Fazendária (CONFAZ) de 2016. Além disso, o imposto pode ser considerado o mais relevante da carga tributária nacional, com a arrecadaçáo representando em torno 6,8\% do PIB brasileiro para valores correntes de 2015.

Segundo Dados do Conselho Nacional de Política Fazendária (CONFAZ), o setor terciário possuiu $41 \%$ da arrecadaçáo do total de ICMS dos estados, o setor secundário, representado pela indústria e construção teve uma arrecadação de $28 \%$ do total e o setor primário teve participação de $1 \%$ no total. Ademais, a arrecadação de ICMS sobre energia elétrica e petróleo e seus derivados representam 25\% do montante arrecadado em 2015.

No tocante a participação dos estados brasileiros na arrecadação total, percebe-se que em 2015 os estados de São Paulo, Minas Gerais e Rio de Janeiro representaram em torno de $50 \%$ da arrecadaçáo, conforme demonstra a Tabela 1 . No período compreendido entre 1997 e 2015 a regiáo sudeste perdeu espaço no comparativo com outras regióes do país, por outro lado, as regiôes nordeste e sul aumentaram suas participaçóes na arrecadação total em 3,1 pontos percentuais (p.p.) e 2,2 p.p. respectivamente. 
Tabela 1: Participação dos estados na arrecadação nacional e regional de ICMS

\begin{tabular}{|c|c|c|c|}
\hline UF & $\begin{array}{l}\text { Participaçáa no total } \\
\text { nacional em } 1997\end{array}$ & $\begin{array}{l}\text { Participaçáo no total } \\
\text { nacional em } 2007\end{array}$ & $\begin{array}{c}\text { Participaçáo no total } \\
\text { nacional em } 2015\end{array}$ \\
\hline NORTE & 4,5 & 5,6 & 6,2 \\
\hline Acre & 0,1 & 0,2 & 0,2 \\
\hline Amazonas & 2,1 & 2,0 & 1,9 \\
\hline Pará & 1,3 & 2,0 & 2,4 \\
\hline Rondônia & 0,6 & 0,8 & 0,8 \\
\hline Amapá & 0,1 & 0,2 & 0,2 \\
\hline Roraima & 0,1 & 0,1 & 0,2 \\
\hline Tocantins & 0,3 & 0,4 & 0,5 \\
\hline NORDESTE & 13,1 & 14,8 & 16,2 \\
\hline Maranhão & 0,7 & 1,1 & 1,3 \\
\hline Piauí & 0,5 & 0,6 & 0,8 \\
\hline Ceará & 2,1 & 2,1 & 2,5 \\
\hline R. do Norte & 0,8 & 1,1 & 1,1 \\
\hline Paraíba & 0,8 & 0,9 & 1,1 \\
\hline Pernambuco & 2,7 & 2,9 & 3,2 \\
\hline Alagoas & 0,6 & 0,7 & 0,8 \\
\hline Sergipe & 0,6 & 0,6 & 0,7 \\
\hline Bahia & 4,3 & 4,8 & 4,7 \\
\hline SUDESTE & 60,5 & 55,5 & 51,9 \\
\hline Minas Gerais & 9,5 & 10,3 & 9,5 \\
\hline E. Santo & 2,7 & 3,1 & 2,5 \\
\hline R. de Janeiro & 8,8 & 8,4 & 8,3 \\
\hline São Paulo & 39,5 & 33,7 & 31,6 \\
\hline SUL & 14,9 & 15,5 & 17,1 \\
\hline Paraná & 4,8 & 5,4 & 6,3 \\
\hline Santa Catarina & 3,4 & 3,6 & 4,0 \\
\hline R. do Sul & 6,7 & 6,5 & 6,8 \\
\hline CENTRO-OESTE & 7,0 & 8,6 & 8,6 \\
\hline Mato Grosso & 1,6 & 2,1 & 2,3 \\
\hline UF & $\begin{array}{l}\text { Participaçáo no total } \\
\text { nacional em } 1997\end{array}$ & $\begin{array}{l}\text { Participaçáo no total } \\
\text { nacional em } 2007\end{array}$ & $\begin{array}{l}\text { Participaçáo no total } \\
\text { nacional em } 2015\end{array}$ \\
\hline M. G. do Sul & 1,1 & 1,9 & 1,1 \\
\hline Goiás & 2,7 & 2,8 & 3,5 \\
\hline Distrito Federal & 1,5 & 1,8 & 1,7 \\
\hline BRASIL & 100,0 & 100,0 & 100,0 \\
\hline
\end{tabular}

Fonte: Conselho Nacional de Política Fazendária - CONFAZ 2016. 
Conforme os dados do CONFAZ (2016) as importações são extremamante concentradas em alguns estados, principalmente nos estados do Sudeste, Sul e em alguns estados mais indistrializados do Nordeste. Tal concentração das importaçóes nesses estados dão uma ideia inicial de que tais estados podem ser os mais afetados pelos efeitos de uma eventual variação no câmbio, porém, em relação ao PIB do estado, suas importações e portanto, a arrecadação do ICMS podem levar a efeitos diferentes que serão avaliados no modelo proposto.

\section{Metodologia}

\subsection{Consideraçóes iniciais sobre modelos VAR}

No início dos anos 1980, novas técnicas estatísticas surgiram com o intuito de analisar um tipo especial de série de dados, as séries temporais. Esses novos modelos foram chamados por Sims (1980) de Vetores Auto-Regressivos (VAR). A característica marcante desse tipo de modelagem é considerar todas as variáveis como endógenas e em função de seus valores defasados.

Essa modelagem emergiu como resposta às críticas ao grande número de restriçóes impostas às estimaçôes pelos modelos estruturais utilizados até então, classificando a priori as variáveis em endógenas e exógenas e impondo restrições nos parâmetros. A ideia era desenvolver modelos dinâmicos com o mínimo de restriçóes, nos quais todas as variáveis fossem tratadas como endógenas (BANCO CENTRAL DO BRASIL, 2004). Para Lutkepohl e Kratzig (2004), os processos VAR são classes de modelos adequados para descrever um processo de geração de dados de uma série pequena ou média. Nesses modelos, todas as variáveis são frequentemente tratadas como endógenas, a priori, e as restriçóes são impostas com base em técnicas estatísticas em vez de crenças anteriores com base no incerto.

Assim, os modelos VAR examinam relações lineares entre cada variável e os valores defasados dela própria e de todas as demais variáveis. Eles tomam em consideração a existência de relaçóes de interdependência entre as variáveis e, permitem avaliar o impacto dinâmico das perturbaçóes aleatórias sobre o sistema de variáveis, o que os tornam particularmente úteis e eficientes na previsão do comportamento futuro de séries temporais inter-relacionadas (CAIADO, 2002).

Assim, a metodologia consistirá na utilização de modelos VAR, pois permitem analisar a importância relativa de cada inovação sobre as variáveis do sistema macroeconômico e descobrir como elas respondem a esse choque simultaneamente, o que é de grande valia para se poder conhecer as possíveis respostas assimétricas dos estados brasileiros à política cambial.

Genericamente, os modelos de estudo são os seguintes:

$\mathrm{X}_{\mathrm{t}}=\mathrm{A}_{1} \cdot \mathrm{X}_{\mathrm{t}-{ }_{1}}+\ldots+\mathrm{A}_{\mathrm{k}} \cdot \mathrm{X}_{\mathrm{t}-{ }_{\mathrm{k}}}+\phi \mathrm{D}_{\mathrm{t}}+\mathrm{u}_{\mathrm{t}}$

Sendo que u $-\mathrm{N}(0, \infty)$. Onde $X_{t}$ é um vetor $(\mathrm{nx} 1)$ de variáveis endógenas e cada elemento $A_{i}$ é uma matriz de parâmetros de ordem (nxn) e $D_{t}$ representa termos 
determinísticos, tais como constantes, tendência linear, dummies, ou qualquer outro tipo de regressor fixo e não estocástico.

Serão estimados 27 modelos VAR, um modelo independente para cada um dos vinte e sete estados analisados. A partir da estimação, são avaliados os comportamentos das funçóes impulso-resposta (FIR), as quais permitem que se destaque a resposta de uma dada variável a um impulso em qualquer outra variável do sistema, ou seja, se investiga a resposta às variações cambiais e seus efeitos no tempo e no espaço.

Para construir o modelo, seguiremos os seguintes passos: ${ }^{3}$ teste de estacionariedade ou presença de raiz unitária, teste de cointegração, teste de causalidade, determinação do número de defasagens necessárias, análise dos resíduos e correção da eventual presença de autocorrelação serial e, por fim, ajustar o modelo de previsão e a função impulso-resposta a ser usada.

\subsection{Variáveis Selecionadas}

Com o objetivo de analisar como o setor real da economia é afetado pelas oscilaçóes cambiais, selecionou-se dados mensais para as séries, apresentadas no Quadro 2, no período de janeiro de 1997 a dezembro 2015, perfazendo um total de 228 observaçóes. As séries foram deflacionadas utilizando-se o IGP-DI.

Quadro 1 - Detalhamento das variáveis incluídas nos modelos ${ }^{4}$

\begin{tabular}{|l|l|l|}
\hline \multicolumn{1}{|c|}{ Variável } & \multicolumn{1}{c|}{ Fonte } & \multicolumn{1}{c|}{ Periodicidade } \\
\hline Taxa real de câmbio real/dólar & $\begin{array}{l}\text { Ipea data. Instituto de Pesquisa } \\
\text { Econômica Aplicada (Ipea) }\end{array}$ & $01 / 1997$ a 12/2015 \\
\hline Arrecadaçáo do ICMS dos estados & CONFAZ & $01 / 1997$ a 12/2015 \\
\hline
\end{tabular}

Fonte: Elaboração própria a partir dos dados da pesquisa.

Para testarmos a presença de quebras estruturais no período, utilizamos o teste de Chow, disponível no programa econométrico. O teste de Chow rejeitou a hipótese de presença de quebras estruturais nos dados em primeira diferença, o que garante a estabilidade do sistema.

As séries de tempo foram dessazonalizadas utilizando-se o método de médias móveis multiplicativo, presente no programa econométrico utilizado, ${ }^{5}$ com o objetivo de filtrar a série de perturbações aleatórias e, após isso, se partiu para os testes dos modelos propriamente ditos.

3 Baseado em Enders (1995) e Lutkepohl (2006).

4 A Tabela 6, nos anexos, traz um quadro que mostra as principais estatísticas descritivas desses dados.

5 Foi utilizado o pacote econométrico Eviews 5.0 para a realização de todos os testes e demais componentes da modelagem do problema descrito. 


\subsection{Estacionariedade e Testes de Raiz Unitária}

Uma condição básica para a aplicação da metodologia VAR é que a série temporal a ser estudada seja estacionária, ${ }^{6}$ ou seja, não apresente tendência ou sazonalidade. Segundo Enders (1995), uma série temporal estacionária é aquela que possui média e variância constante ao longo do tempo e o valor da covariância entre dois períodos de tempo depende apenas da distância entre os dois períodos.

Os testes Phillips-Perron em nível e em primeira diferença tiveram como resultados os mostrados na Tabela 2 . Todas as séries são estacionárias em nível a $5 \%$ de significância, à exceção das séries para Paraíba e Pernambuco e do próprio câmbio real, que são estacionários apenas em primeira diferença, o que leva o VAR a ser construído em primeira diferença ${ }^{7}$.

Tabela 2 - Testes de estacionariedade e raiz unitária de Phillips-Perron

\begin{tabular}{l|l|l|l|l|l|l}
\hline \multicolumn{1}{c|}{ Variável } & \multicolumn{3}{c|}{ Em nível I(0) } & \multicolumn{3}{c}{ Primeira diferença I(1) } \\
\hline & Estatísticas t & $5 \%$ significância & P-valor & Estatísticas t & $5 \%$ significância & P-valor \\
\hline ICMS AC & -9.448548 & -3.429745 & 0.0000 & & & \\
\hline ICMS AL & -9.181294 & -3.429745 & 0.0000 & & & \\
\hline ICMS AM & -10.93628 & -3.429745 & 0.0000 & & & \\
\hline ICMS AP & -7.945208 & -3.429745 & 0.0000 & & & \\
\hline ICMS BA & -5.961471 & -3.429745 & 0.0000 & & & \\
\hline ICMS CE & -4.791298 & -3.429745 & 0.0004 & & & \\
\hline ICMS DF & -6.988333 & -3.429745 & 0.0000 & & & \\
\hline ICMS ES & -8.342711 & -3.429745 & 0.0000 & & & \\
\hline ICMS GO & -8.714668 & -3.429745 & 0.0000 & & & \\
\hline ICMS MA & -6.425649 & -3.429745 & 0.0000 & & & \\
\hline ICMS MG & -5.756024 & -3.429745 & 0.0000 & & & \\
\hline ICMS MS & -3.221824 & -3.429745 & 0.0000 & & & \\
\hline ICMS MT & -4.966225 & -3.429745 & 0.0000 & & & \\
\hline ICMS PA & -4.966225 & -3.429745 & 0.0000 & & & \\
\hline ICMS PB & -3.083802 & -3.429745 & 0.1136 & -31.19219 & -3.429745 & 0,0000 \\
\hline ICMS PE & -2.551599 & -3.429745 & 0.3020 & -26.02493 & -3.429745 & 0,0000 \\
\hline ICMS PI & -7.097244 & -3.429745 & 0.0000 & & & \\
\hline ICMS PR & -10.45562 & -3.429745 & 0.0000 & & & \\
\hline
\end{tabular}

6 Há distinção entre séries que apresentam estacionaridade fraca ou estrita, porém a condição frequentemente utilizada na literatura é a primeira, de modo que os termos estacionaridade, estacionaridade fraca e covariância estacionária são utilizados de forma intercambiável. Para mais detalhes sobre o conceito e as diferenças entre essas duas propriedades das séries, ver Bueno (2008), Enders (1995) e Lutkepohl e Kratzig (2004).

7 Tendo em vista que o câmbio real faz parte de todos os modelos, mesmo aquelas séries que foram estacionárias em nível tiveram que ser diferenciadas, haja vista que a série de câmbio real foi estacionária apenas em I(1). 


\begin{tabular}{l|l|l|l|l|l|l}
\hline \multicolumn{1}{c|}{ Variável } & \multicolumn{3}{c|}{ Em nível I(0) } & \multicolumn{3}{c}{ Primeira diferença I(1) } \\
\hline & Estatísticas t & $5 \%$ significância & P-valor & Estatísticas t & $5 \%$ significância & P-valor \\
\hline ICMS RJ & -6.741830 & -3.429745 & 0.0000 & & & \\
\hline ICMS RN & -12.70492 & -3.429745 & 0.0000 & & & \\
\hline ICMS RO & -4.617107 & -3.429745 & 0.0000 & & & \\
\hline ICMS RR & -7.222495 & -3.429745 & 0.0000 & & & \\
\hline ICMS RS & -9.930141 & -3.429745 & 0.0000 & & & \\
\hline ICMS SC & -6.55748 & -3.429745 & 0.0008 & & & \\
\hline ICMS SE & -9.783564 & -3.429745 & 0.0000 & & & \\
\hline ICMS SP & -1.584014 & -3.429745 & 0.0000 & & & \\
\hline ICMS TO & -5.854846 & -3.429745 & 0.0000 & & & 0,0000 \\
\hline CÂMBIO REAL & -1.867331 & -2.874086 & 0.3474 & -10.36782 & -2.886074 & \\
\hline
\end{tabular}

Fonte: Elaboração própria a partir dos dados da pesquisa.

\subsection{Cointegraçáo e o teste de Johansen}

O teste de cointegração visa determinar se há influências mútuas nas trajetórias de longo prazo de duas ou mais séries temporais e qual o número de vetores de cointegração que serão necessários ao sistema. Mais especificamente, esse teste permite determinar se as variáveis de interesse possuem ou não um relacionamento, um equilíbrio de longo prazo ${ }^{8}$.

Dentre os testes de cointegração, cujo objetivo é determinar se um grupo de variáveis não-estacionárias são cointegradas e se a combinação linear entre elas gera uma variável estacionária, o teste de Johansen é o mais utilizado. No teste, Johansen (1988) propóe duas estatísticas. A primeira (estatística do Traço ) testa a hipótese nula de que o número de vetores de cointegração distintos é menor ou igual a r (número de vetores de cointegraçáo), contra a hipótese alternativa de que ele é maior que r. A segunda estatística (estatística do Máximo Autovalor) testa a hipótese nula de que o número de vetores de cointegração é r, contra a hipótese alternativa de que o número de vetores é $\mathrm{r}+1$.

Geralmente, adota-se apenas uma das estatísticas anteriormente descritas. Os resultados do teste, apresentados na Tabela 3, dependem do número de lags da equaçáo. Para a escolha do número de lags, Enders (1995) propóe que sejam estimados modelos VAR de diferentes ordens para as variáveis em nível objeto do teste e seja escolhido o número de defasagens igual à ordem do modelo com os menores valores para os critérios Akaike e Schwarz.

8 A definição formal de Cointegração encontra-se em Engle e Granger (1987). 
Tabela 3: Resultados dos testes de Cointegração de Johansen

\begin{tabular}{|c|c|c|c|}
\hline Variável & Estatística do Traço & Valor Crítico 5\% & P-valor* \\
\hline ICMS AC & 51.28335 & 18.39771 & 0 \\
\hline ICMS AL & 23.16531 & 18.39771 & 0,0099 \\
\hline ICMS AM & 24.34344 & 18.39771 & 0,0065 \\
\hline ICMS AP & 31.46070 & 18.39771 & 0,0004 \\
\hline ICMS BA & 40.73236 & 18.39771 & 0 \\
\hline ICMS CE & 22.47264 & 18.39771 & 0,0127 \\
\hline ICMS DF & 55.40937 & 18.39771 & 0 \\
\hline ICMS ES & 74.48555 & 18.39771 & 0,0001 \\
\hline ICMS GO & 28.19127 & 18.39771 & 0,0016 \\
\hline ICMS MA & 23.19196 & 18.39771 & 0,0099 \\
\hline ICMS MG & 21.07433 & 18.39771 & 0,0206 \\
\hline ICMS MS & 20.25287 & 18.39771 & 0,0273 \\
\hline ICMS MT & 34.26480 & 18.39771 & 0,0001 \\
\hline ICMS PA & 18.84556 & 18.39771 & 0,0433 \\
\hline ICMS PB & 18.49916 & 18.39771 & 0,0484 \\
\hline ICMS PE & 20.84504 & 18.39771 & 0,0223 \\
\hline ICMS PI & 18.44695 & 18.39771 & 0,0492 \\
\hline ICMS PR & 3585242 & 18.39771 & 0,0001 \\
\hline ICMS RJ & 21.15856 & 18.39771 & 0,0291 \\
\hline ICMS RN & 1877562 & 18.39771 & 0,0433 \\
\hline ICMS RO & 2388521 & 18.39771 & 0,0077 \\
\hline ICMS RR & 20.66253 & 18.39771 & 0,0237 \\
\hline ICMS RS & 35.06389 & 18.39771 & 0,0001 \\
\hline ICMS SC & 25.49098 & 18.39771 & 0,0043 \\
\hline ICMS SE & 29.74324 & 18.39771 & 0,0099 \\
\hline ICMS SP & 28.74017 & 18.39771 & 0,0013 \\
\hline ICMS TO & 22.54939 & 18.39771 & 0,0124 \\
\hline
\end{tabular}

Hipótese nula: ausência de Cointegraçáo.

* Denota rejeição da hipótese nula a 5\% de significância.

Fonte: elaboração do autor com dados da pesquisa.

Para os dados em análise, após a aplicação do teste, como definido acima, houve cointegração entre as variáveis para todas as séries (para todos os estados), como mostra a Tabela 2. 


\subsection{Causalidade e o teste de Granger}

O teste de causalidade proposto por Granger (1969) visa superar as limitaçóes do uso de simples correlaçōes entre variáveis, pois correlação não implica por si só em causalidade (relação de causa e efeito). Assim, uma variável $\mathrm{X}$ causa outra variável $\mathrm{Z}$ no sentido de Granger se a observaçáo de $\mathrm{X}$ no presente ou no passado ajuda a prever os valores futuros de $\mathrm{Z}$ para algum horizonte de tempo.

A esse respeito, Carneiro (1997) afirma que a identificação de uma relação estatística entre duas ou mais variáveis, por mais forte que seja, não pode estabelecer uma relação causal entre elas. Para ele, qualquer relação de causalidade deve se originar de fora da estatística, baseando-se, fundamentalmente em uma teoria já estabelecida.

A relação de causalidade entre as variáveis é fundamental dentro da análise de séries temporais, pois apesar de a análise de regressão lidar com dependência de uma variável em relaçáo a outras, esta dependência não implica relaçáo de causalidade. Como o futuro não pode prever o passado, se a variável $\mathrm{X}$ causa (no sentido Granger) a variável $\mathrm{Y}$, então mudanças em $\mathrm{X}$ devem preceder mudanças em $\mathrm{Y}$.

Em termos formais, o teste envolve estimar as seguintes regressóes?:

$$
\begin{aligned}
& X_{t}=\sum a_{i} Y_{t-i}+\sum b_{i} X_{t-i}+u_{1 t} \\
& Y_{t}=\sum c_{i} Y_{t-i}+\sum d_{i} X_{t-i}+u_{2 t}
\end{aligned}
$$

onde $\mathrm{u}_{\mathrm{it}}$ são os resíduos que assume-se serem não-correlacionados.

A primeira equação postula que valores correntes de $\mathrm{X}$ estão relacionados a valores passados do próprio $\mathrm{X}$ assim como a valores defasados de $\mathrm{Y}$; a segunda equação, postula um comportamento similar para a variável Y. Nada impede que as variáveis X e Y sejam representadas na forma de taxas de crescimento, o que aliás tem sido quase que a regra geral na literatura, uma vez que é difícil achar variáveis que sejam estacionárias em seus níveis (CARNEIRO, 1997).

Os resultados para o teste de causalidade de Granger, estão apresentados na Tabela 4, abaixo. Houve causalidade no sentido de Granger para todas as variáveis, com significância de 5\%, à exceção do estado do Amazonas, Maranhão, Mato Grosso do Sul, Mato Grosso, Pará, Rondônia e Santa Catarina, que não são causados no sentido de Granger pelo câmbio real, ou seja, se a observação do câmbio real no presente $(\mathrm{t})$ ou no passado (t-i) ajuda a prever os valores futuros da arrecadação de ICMS para algum horizonte de tempo, com $95 \%$ de confiança.

9 Baseado em Carneiro (1997) e Enders (1995). 
Tabela 4 - Testes de causalidade de Granger

\begin{tabular}{|c|c|c|c|}
\hline Variável & Estatística $F$ & P-valor* & LAGs \\
\hline ICMS AC & 4.13762 & 0.0172 & 2 \\
\hline ICMS AL & 7.53199 & 0,0066 & 1 \\
\hline ICMS AM & 3.65150 & $0,0573^{*}$ & 1 \\
\hline ICMS AP & 4.18899 & 0,0419 & 1 \\
\hline ICMS BA & 3.91829 & 0,049 & 1 \\
\hline ICMS CE & 4.28828 & 0,0395 & 1 \\
\hline ICMS DF & 8.43601 & 0 & 1 \\
\hline ICMS ES & 1.38336 & 0,0003 & 1 \\
\hline ICMS GO & 4.96302 & 0,0269 & 1 \\
\hline ICMS MA & 3.56363 & $0,0604^{*}$ & 1 \\
\hline ICMS MG & 5.84981 & 0,0164 & 1 \\
\hline ICMS MS & 0.46681 & $0,4952^{*}$ & 1 \\
\hline ICMS MT & 1.11779 & $0,2915^{*}$ & 1 \\
\hline ICMS PA & 2.55493 & $0,1114^{*}$ & 1 \\
\hline ICMS PB & 2.45191 & 0,0348 & 2 \\
\hline ICMS PE & 5.57583 & 0,0043 & 1 \\
\hline ICMS PI & 2.66944 & 0,0231 & 2 \\
\hline ICMS PR & 4.37589 & 0,0376 & 2 \\
\hline ICMS RJ & 7.65269 & 0,0061 & 1 \\
\hline ICMS RN & 2.78718 & 0,0416 & 3 \\
\hline ICMS RO & 3.54895 & $0,0699^{*}$ & 1 \\
\hline ICMS RR & 4.72086 & 0,0308 & 1 \\
\hline ICMS RS & 6.59243 & 0,0109 & 1 \\
\hline ICMS SC & 2.34205 & $0,0560^{*}$ & 4 \\
\hline ICMS SE & 5.50086 & 0,0199 & 1 \\
\hline ICMS SP & 5.56651 & 0,0044 & 1 \\
\hline ICMS TO & 3.68255 & 0,0128 & 3 \\
\hline
\end{tabular}

* Denota rejeição da hipótese nula a 5\% de significância.

Fonte: elaboração do autor, com dados da pesquisa.

Além de ter permitido definir a presença ou não de causalidade entre as variáveis dos modelos, o teste de Granger foi um primeiro indicativo do número de defasagens para a estimação do VAR e das funções impulso-resposta. O número de defasagens será definido pelo teste de Schwarz, como apresentado posteriormente.

\subsection{Seleçáo de Defasagens do Modelo e Análise dos Resíduos}

Quanto ao número de defasagens a serem aplicadas ao modelo, é utilizado o Schwarz Bayesian Criterion (SBC). Como a escolha da ordem de defasagem do VAR é arbitrária, 
o desejável é incluir o maior número de defasagens de modo a evitar a imposição de restrições falsas sobre a dinâmica do modelo. Entretanto, a parcimônia se coloca como fator fundamental nessa escolha, à medida que, quanto maior o lag utilizado, maiores os graus de liberdade consumidos ${ }^{10}$.

Todos os critérios utilizam o mesmo método de seleção, com algumas diferenças entre si, como minimizar a soma dos quadrados dos resíduos (SQR). Como ressaltado por Enders (1995) e Bueno (2008), o SBC possui propriedades assintóticas superiores aos demais critérios, tendendo a selecionar um modelo mais parcimonioso. O critério de Schwarz tem como pressuposto a existência de um "modelo verdadeiro" que descreve a relação entre a variável dependente e as diversas variáveis explanatórias entre os diversos modelos sob seleção. Assim, o critério é definido como a estatística que maximiza a probabilidade de se identificar o verdadeiro modelo entre os avaliados. Os resultados dos testes encontram-se na Tabela 5.

Tabela 5 - Seleção de defasagens do modelo - critério de Schwarz

\begin{tabular}{|c|c|c|c|}
\hline Variável & Schwarz SC & Lag & $\begin{array}{l}\text { Lag após correçáo de } \\
\text { autocorrelaçáo }\end{array}$ \\
\hline ICMS AC & 26.98065 & 1 & 2 \\
\hline ICMS AL & 29.08740 & 2 & 4 \\
\hline ICMS AM & 30.41960 & 1 & 2 \\
\hline ICMS AP & 26.77345 & 2 & 2 \\
\hline ICMS BA & 32.49305 & 2 & 3 \\
\hline ICMS CE & 30.58205 & 1 & 2 \\
\hline ICMS DF & 30.74307 & 3 & 3 \\
\hline ICMS ES & 31.81826 & 1 & 1 \\
\hline ICMS GO & 32.40200 & 2 & 2 \\
\hline ICMS MA & 2908322 & 1 & 1 \\
\hline ICMS MG & 33.65226 & 2 & 2 \\
\hline ICMS MS & 29.13454 & 1 & 1 \\
\hline ICMS MT & 29.78517 & 1 & 1 \\
\hline ICMS PA & 30.94757 & 1 & 1 \\
\hline ICMS PB & 28.45323 & 1 & 2 \\
\hline ICMS PE & 30.25896 & 1 & 1 \\
\hline ICMS PI & 28.40612 & 2 & 2 \\
\hline ICMS PR & 33.18955 & 2 & 2 \\
\hline ICMS RJ & 33.31690 & 2 & 4 \\
\hline
\end{tabular}

10 A determinação do número de defasagens de um modelo dinamico (lags) consiste em identificar o menor número de defasagens nas variáveis regressoras que devam ser incluídas no modelo de modo que ele explique adequadamente a variável resposta. Para mais informaçóes ver Furlan (2009). 


\begin{tabular}{l|c|c|c}
\hline \multicolumn{1}{c|}{ Variável } & Schwarz SC & Lag & $\begin{array}{c}\text { Lag após correçáo de } \\
\text { autocorrelaçáo }\end{array}$ \\
\hline ICMS RN & 28.68844 & 2 & 2 \\
\hline ICMS RO & 29.16858 & 1 & 1 \\
\hline ICMS RR & 25.63088 & 2 & 2 \\
\hline ICMS RS & 32.92073 & 2 & 2 \\
\hline ICMS SC & 31.00406 & 2 & 2 \\
\hline ICMS SE & 28.93310 & 2 & 2 \\
\hline ICMS SP & 36.28683 & 2 & 2 \\
\hline ICMS TO & 26.52688 & 2 & \\
\hline
\end{tabular}

Fonte: Elaboração própria a partir dos dados da pesquisa.

A análise dos resíduos e eventual correção de autocorrelação serial foi feita nessa fase do trabalho, utilizando-se do teste de autocorrelação serial LM. ${ }^{11}$ Nos modelos em que houve evidência de autocorrelação, estimou-se um VAR de ordem (lag) superior até que a autocorrelação fosse eliminada.

\section{Análise dos resultados e Funçóes Impulso-Resposta (FIR)}

A FIR parte do princípio de que um choque na $i$-ésima variável não apenas afeta diretamente os seus valores, mas também é transmitido para todas as outras variáveis endógenas através de uma estrutura dinâmica (defasada) dentro do sistema VAR. Em outras palavras, a FIR mostra qual será o comportamento das variáveis ao longo do tempo quando algum dos resíduos sofrer uma modificação no seu valor (choques exógenos, conhecidos como inovaçóes). Portanto, a FIR pode ser considerada como uma simulação para o comportamento de um VAR ao longo do tempo, diante de um choque em algum dos resíduos (ANDRADE, 2006).

Com o objetivo de simular o comportamento ao longo do tempo das variáveis envolvidas no modelo, analisa-se as funçóes impulso-resposta subjacentes a cada um dos modelo VAR estimados. Busca-se, com isso, apresentar o comportamento dinâmico das variáveis frente a choques exógenos no câmbio, por estado da federação.

\subsection{Efeitos Dinâmicos dos Choques Cambiais nos Estados Brasileiros}

As funçóes impulso-resposta apresentadas na Figura 3, do apêndice 1, representam as respostas da arrecadação de ICMS em cada estado para um choque positivo no nível de câmbio (uma desvalorização cambial). Pode-se observar que há, no geral, um padrão de comportamento em todos os estados, contudo, ao se avaliar a resposta em cada estado, percebe-se que os efeitos são bastante diferenciados na sua intensidade e temporariedade.

A maioria das respostas da arrecadação do ICMS ao impulso dado no câmbio real foi negativa. Vinte e um dos 27 estados brasileiros tiveram esse padrão de resposta ao choque

11 Teste do multiplicador de Lagrange, usado para detectar a autocorrelação nos resíduos. 
exógeno na variável de impulso, sendo as respostas significativas e estatisticamente diferntes de zero. Amazonas, Espirito Santo, Goiás, Maranhão, Mato Grosso do Sul e Paraná foram os estados que distoaram desse padrão de respostas, apresentando variaçóes positivas na arrecadação do ICMS estadual como respostas a desvalorizaçōes cambiais.

Dentre os estados que retornaram respostas não convencionais para variaçóes na arrecadação do ICMS, o padrão de temporariedade das respostas foi entre 2 e 3 meses de duração do choque, ou seja, a variável ICMS teve seu pico de resposta positiva entre 2 e 3 meses após o choque no câmbio real, como pode ser visto na Figura 1, que representa a FIR do Paraná.

Figura 1 - Função impulso-resposta do estado do Paraná

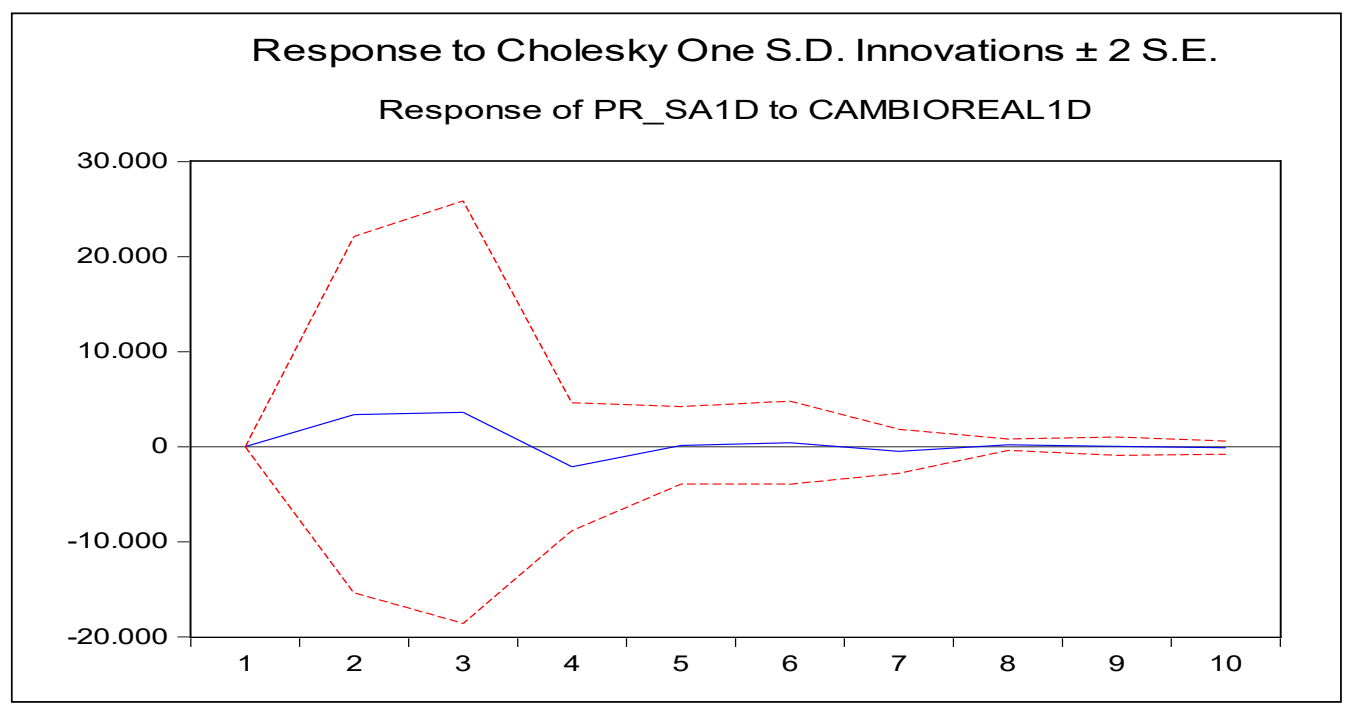

Fonte: Elaboração própria a partir dos dados da pesquisa.

Acre, Alagoas, Amapá, Bahia, Ceará, Distrito Federal, Minas Gerais, Mato Grosso, Pará, Paraíba, Pernambuco, Piauí, Rio de Janeiro, Rio Grande do Norte, Rondônia, Roraima, Rio Grande do Sul, Santa Catarina, Sergipe, São Paulo e Tocantins são os estados que apresentam uma resposta convencional às desvalorizaçóes na taxa de câmbio real, ou seja, há quedas na arrecadação de ICMS, frente a um choque cambial de um desvio-padrão, com o ponto de inflexão sendo atingido entre dois e três meses após o choque. Pode-se observar também que o efeito overshooting aparece nos estados do CE, DF, PE, PI, RN, RR, RS, SC, SE, SP e TO. Na Figura 2 temos, como exemplo, a FIR do Rio Grande do Sul. 
Figura 2 - Função Impulso-resposta do estado do Rio Grande do Sul

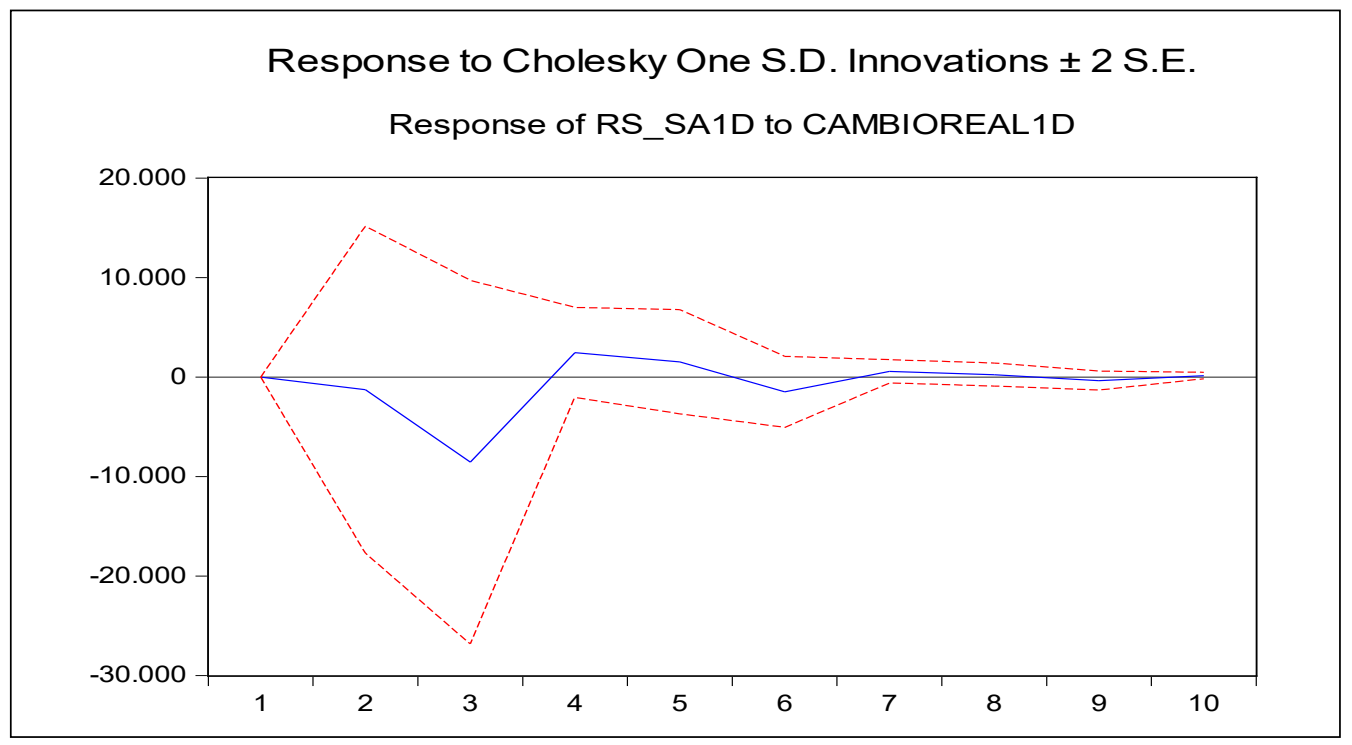

Fonte: Elaboração própria a partir dos dados da pesquisa.

Em termos do tamanho do efeito, o modelo apresentou variaçóes entre $-1,9 \%$ e $+1,1 \%$ para choques de um desvio-padrão no câmbio real. Os efeitos mais pronunciados aparecem nos estados do Norte e Nordeste, com variações na arrecadação entre $-1,9 \%$ e $-0,7 \%$ (AC, PI, SE, SP, RN, AP, TO, DF, PE), como pode ser visto na Tabela 6. Nesse grupo, a exceção é SP, que não se localiza naquelas regióes mas teve variação na arrecadação de ICMS bastante pronunciada.

No grupo de estados que apresentaram respostas intermediárias à variação de um desvio-padrão no câmbio, temos SC, CE, RR, RS, AL, RJ, PA, MG, MT, BA, RO, PB com variaçóes entre $-0,6 \%$ e $-0,2 \%$, como pode ser visto na Tabela 6 . Neste grupo, há representantes de todas as regióes brasileiras, não permitindo assim tirarmos conclusóes acerca da assimetria das respostas entre as regióes brasileiras.

$\mathrm{Na}$ outra ponta, os estados que apresentaram respostas positivas às variaçóes do câmbio, temos respostas entre $0,1 \%$ e $1,1 \%$ para PR, MS, MA, AM, GO e ES. Nesse grupo, o destaque é o estado do PR, que é um dos cinco estados com maior arrecadação de ICMS do Brasil, e apresentou respostas pouco sensíveis de sua arrecadação de ICMS às variaçóes na taxa de câmbio real. 
Tabela 6 - Resultados do Modelo VAR

\begin{tabular}{|c|c|c|c|}
\hline Estados & $\begin{array}{c}\text { Média ICMS período / } \\
\text { importaçóes }\end{array}$ & $\begin{array}{c}\text { Importaçóes / PIB } \\
2015\end{array}$ & Efeitos do VAR \\
\hline Acre & $1 \%$ & 0,3 & $-1,9 \%$ \\
\hline Piauí & $4 \%$ & 2,5 & $-1,2 \%$ \\
\hline São Paulo & $84 \%$ & 55,3 & $-1,1 \%$ \\
\hline Sergipe & $13 \%$ & 7,7 & $-1,1 \%$ \\
\hline Rio Grande do Norte & $8 \%$ & 4,9 & $-1,1 \%$ \\
\hline Tocantins & $8 \%$ & 4,6 & $-0,9 \%$ \\
\hline Amapá & $5 \%$ & 2,0 & $-0,9 \%$ \\
\hline Distrito Federal & $75 \%$ & 24,4 & $-0,8 \%$ \\
\hline Pernambuco & $73 \%$ & 50,2 & $-0,7 \%$ \\
\hline Santa Catarina & $149 \%$ & 85,3 & $-0,6 \%$ \\
\hline Ceará & $47 \%$ & 31,8 & $-0,6 \%$ \\
\hline Rio Grande do Sul & $59 \%$ & 39,7 & $-0,5 \%$ \\
\hline Alagoas & $41 \%$ & 26,0 & $-0,5 \%$ \\
\hline Roraima & $5 \%$ & 2,2 & $-0,5 \%$ \\
\hline Rio de Janeiro & $91 \%$ & 42,3 & $-0,4 \%$ \\
\hline Minas Gerais & $43 \%$ & 28,3 & $-0,4 \%$ \\
\hline Mato Grosso & $29 \%$ & 21,0 & $-0,4 \%$ \\
\hline Pará & $27 \%$ & 13,6 & $-0,4 \%$ \\
\hline Bahia & $67 \%$ & 50,2 & $-0,3 \%$ \\
\hline Rondônia & $39 \%$ & 30,1 & $-0,3 \%$ \\
\hline Paraíba & $18 \%$ & 12,1 & $-0,2 \%$ \\
\hline Paraná & $101 \%$ & 54,3 & $0,03 \%$ \\
\hline Mato Grosso do Sul & $88 \%$ & 70,0 & $0,2 \%$ \\
\hline Amazonas & $183 \%$ & 138,7 & $0,4 \%$ \\
\hline Maranhão & $74 \%$ & 36,4 & $0,4 \%$ \\
\hline Goiás & $53 \%$ & 34,5 & $0,6 \%$ \\
\hline Espírito Santo & $85 \%$ & 63,2 & $1,1 \%$ \\
\hline $\begin{array}{l}\text { Correlaçáo de Person } \\
\text { com efeitos do VAR }\end{array}$ & 0,51 & 0,55 & 1,00 \\
\hline
\end{tabular}

Fonte: Elaboração própria a partir dos dados da pesquisa.

Quanto aos prováveis motivos que levam os estados a apresentarem diferentes comportamentos frente a um choque comum no câmbio, nossa hipótese principal é a de que estados que tem um menor índice de importaçóes são mais afetados pelo câmbio, haja vista a importação ser fato gerador de ICMS. Já as exportaçōes são totalmente desoneradas do pagamento desse tributo pela Constituição Federal de 1988. 
Como pode ser observado na Tabela 6, os maiores efeitos negativos se deram justamente naqueles estados com baixa participação relativa das importações no seu PIB, ou seja, os resultados negativos aparecem mais, pronunciadamente, onde há baixo coeficiente de impotaçóes na economia local. Já aqueles estados que apresentam participação relativamente grande das importaçóes na sua economia, apresentaram efeitos pequenos, ou até mesmo positivos, como é o caso de AM, SC, PR e RJ.

Esse comportamento indica que outros canais de transmissão do câmbio para a arrecadação estão agindo nos estados brasileiros, que não diretamente a tributação dos produtos importados do exterior pelo ICMS. Entre esses possíveis canais de transmissão das variaçóes do câmbio para a arrecadação de ICMS, podemos citar: o dinamismo das economias regionais, haja vista que os dados demonstram que pequenas economias têm efeitos mais pronunciados do que as grandes economias estaduais e também a chamada 'guerra fiscal' mais especificamente a 'guerra dos portos', haja vista que estados que participam ativamente desta 'guerra', como Santa Catarina, estão entre aqueles mais atingidos negativamente pelos efeitos do câmbio.

\section{Consideraçóes Finais}

O objetivo geral do artigo foi averiguar se a política de câmbio produz resultados assimétricos sobre a arrecadação de ICMS dos diferentes estados brasileiros. Com base nos resultados, as assimetrias nas respostas frente a choques macroeconômicos comuns foram confirmadas, já que são constatados impactos regionalmente diferenciados na amostra utilizada, comprovando que características como diversidade econômica, estrutura produtiva e inserção no comércio internacional dos estados são de suma importância para explicar os diferentes níveis de impactos, com diferenças bastante acentuadas na intensidade e temporariedade das respostas.

Quanto aos resultados encontrados para a política cambial, no geral os estados das regióes Norte, Nordeste e Centro-Oeste são os mais afetados, em contraste com os estados do Sul e Sudeste. Esses estados parecem ser negativamente afetados pela baixa participação de suas economias no comércio internacional e pela baixa diversidade produtiva local. Os estados com baixa participação no PIB nacional como um todo e com baixas correntes de comércio são justamente os mais afetados pelo câmbio.

Já no grupo de estados com baixa sensibilidade à taxa de câmbio, destacam-se os estados do Sul e Sudeste, com participações relativamente grandes no total de importaçóes nacionais, bem como grande participação no PIB nacional, além de possuir estruturas produtivas bem desenvolvidas, com boa diversidade produtiva.

Esse comportamento demonstrado na pesquisa é condizente com os estudos de Ramos et al. (2001), os quais apontam que regióes em que a diversidade produtiva se restringe a poucas atividades onde há forte concentração do valor adicionado em poucas indústrias, sentirão o impacto por mais tempo e de forma mais intensa de variaçóes na taxa de câmbio. De outro modo, regióes que possuem forte diversificação de atividades econômicas sentem menos o impacto de um choque cambial comum. 
Os resultados deste trabalho podem abrir uma nova frente de pesquisa, até agora não abordada na literatura nacional conhecida, que são os efeitos assimétricos de choques cambiais com perspectiva regional. Além disso, suas consequências e possíveis medidas para amenizar tais efeitos, além de trazer novos dados e conclusóes sobre uma área já bastante estudada, que são os impactos assimétricos da política cambial, tendo como nexo causal as heterogeneidades geográficas e seus efeitos sobre a arrecadação de tributos (ICMS).

\section{Referências}

ANDRADE, D. C. Fatores condicionantes do crescimento econômico de longo prazo na China: aspectos teóricos e investigação empírica. 2006. 137 f., Dissertaçáo (Mestrado em Economia) - Programa de Pós-Graduação em Economia. Universidade Federal de Uberlândia, Uberlândia, 2006.

BOISIER, S. Política econômica, organização social e desenvolvimento regional. In HADDAD, P. R. (Org.). Economia regional: teoria e métodos de análise. Fortaleza: BNB, 1989. p. 111-145.

BONELLI, R. O desempenho exportador das firmas industriais brasileiras e o contexto macroeconômico. Brasília, DF: Ipea, 2005.

BRAATZ, J; MORAES, G, I. IMPACTOS REGIONAIS ASSIMÉTRICOS DA POLÍTICA CAMBIAL NO BRASIL: UMA ABORDAGEM COM O MÉTODO VAR. Revista Análise Econômica, Porto Alegre, v. 34, no 65, p. 47-73, 2016.

BRAATZ, J; MORAES, G, I. Impactos regionais assimétricos da política monetária no brasil: uma abordagem com o método VAR para o período 2002-2011. Ensaios FEE, Porto Alegre, v. 37, no 2, p. 368-398, 2016.

BUENO, R. L. S. Econometria de séries temporais. São Paulo: Cengage, 2008. v. 1.

CAIADO, J. Cointegração e causalidade entre as taxas de juros e a inflação em Portugal. Gestin, v. 1, n. 1, p. 107-118, 2002.

CARLINO, G. A.; DEFINA, R. The differential regional effects of monetary policy: evidence from the U.S. states. Philadelphia: FRB, 1997. (Trabalho para Discussão, n 97).

CONSELHO NACIONAL DE POLÍTICA FAZENDÁRIA-CONFAZ. Disponível em <https:// www.confaz.fazenda.gov.br/legislacao/boletim-do-icms>. Acessado em: 06/04/2016.

EICHENGREEN, B. Is Europe an optimum currency area? Cambridge, MA: University of California, Working Paper, n. 3579, 1991.

ENDERS, W. Applied econometric time series. New York: John Wiley e Sons, 1995.

FURLAN, Camila Pedrozo Rodrigues. Especificação do tamanho de defasagem de um modelo dinâmico. Dissertaçáo de Mestrado. Programa de Pós-Graduação em Economia. UFSCAR, 2009. $116 p$. 
HADDAD, E. A.; DOMINGUES, E. P.; PEROBELLI, F. S. Impactos setoriais e regionais da integração. Brasília, DF: Ipea, p. 235-278. 2001.

INSTITUTO DE PESQUISA ECONÔMICA APLICADA. Ipeadata. Disponível em: <www. ipeadata.gov.br>. Acesso em: 28/02/2016.

KOUPARITSAS, M. A. Is the United States an optimum currency area? An empirical analysis of regional business cycles. Chicago: Federal Reserve Bank of Chicago, 2001.

KUME, H.;PIANI, G. Efeitos regionais do MERCOSUL: uma análise diferencial-estrutural para o período 1990/1995. Rio de Janeiro. Ipea, agosto de 1998. (Texto para Discussão, n. 585).

LUTKEPOHL, H. New Introduction to Multiple Time Series Analysis. New York: SpringerVerlag, 2006.

LUTKEPOHL, H.; KRATZIG, M.; Applied time series econometrics. Cambridge: Cambridge University Press, 2004.

MYRDAL, G. Teoria econômica e regióes subdesenvolvidas. 2. ed. Rio de Janeiro: Saga, 1968.

RAMOS, R.; OLLERO, J. L.; SURIÑACH, J. Macroecomic Implications of EMU at the Regional Level. In: CONGRESS OF THE EUROPEAN REGIONAL SCIENCE ASSOCIATION, 41, 2001. p. 190-210.

SECRETARIA DE POLÍTICA ECONÔMICA DO MINISTÉRIO DA FAZENDA. Relatório de Análise Econômica dos Gastos Públicos Federais Evoluçáo dos Gastos Públicos Federais no Brasil: Uma análise para o período 2006-15. Disponível em: <http://www.fazenda.gov.br/centraisde-conteudos/publicacoes/relatorio-de-analise economica-dos-gastos-publicosfederais/relatorio_ gasto_publico_federal_site.pdf>. Acessado em: 15/08/2016.

SECRETARIA DO TESOURO NACIONAL. Resultado fiscal do Governo Central. Disponível em: <http://www.tesouro.fazenda.gov.br/resultado-do-tesouro-nacional>. Acessado em: 20/08/2016.

\section{SECRETARIA DO TESOURO NACIONAL. Consolidaçáo das Contas Públicas: Exercício}

2015. Disponível em: <http://www.tesouro.fazenda.gov.br/documents/10180/390400/CCP+2015. pdf/b4635ba8-dfff-41a8-91ee-2b0ffc4e961f >. Acessado em: 20/08/2016.

SIMS, C. A. Macroeconomics and Reality. Econometrica, v. 48, n. 1, p. 1-48, Jan. 1980.

VERÍSSIMO, M. P.; SILVA, C. G. Uma investigação sobre a hipótese da doença holandesa nas regiōes brasileiras. In: ENCONTRO INTERNACIONAL DA ASSOCIAÇÃO KEYNESIANA BRASILEIRA, 4., 2011, Rio de Janeiro. Anais... Rio de Janeiro, 2011. p. 01-19.

WYPLOSZ, C. Regional Exchange rate arrangements: lessons from Europe for East Asia. Geneva: CEPR, October 2002. (Working Paper, nº. 116). 


\section{Apêndice 1}

Figura 3 - Funçóes impulso-resposta do VAR
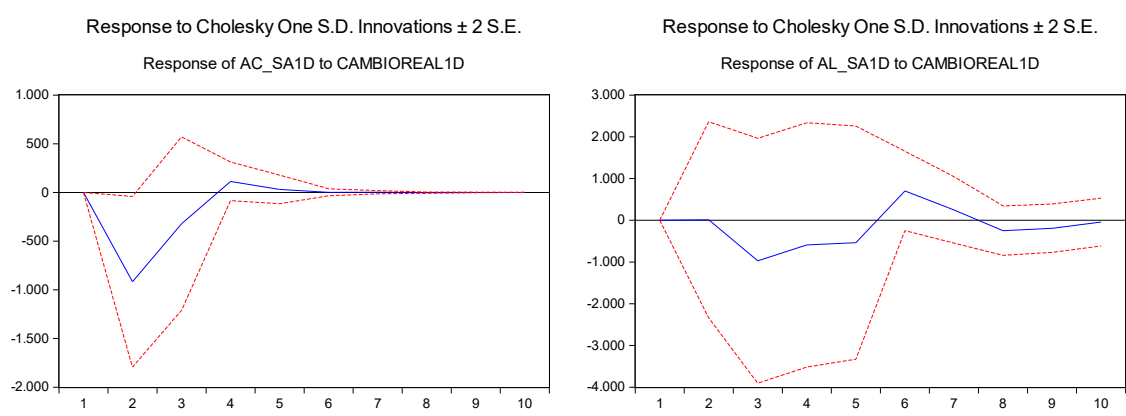

Response to Cholesky One S.D. Innovations \pm 2 S.E.

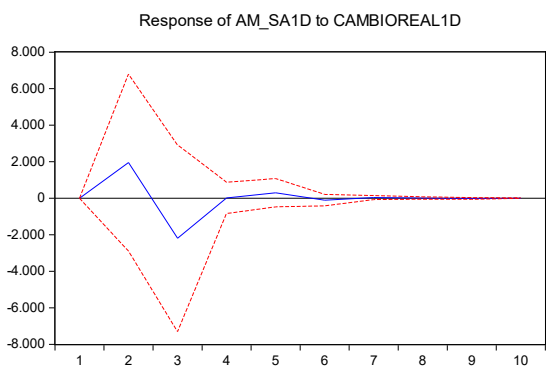

Response to Cholesky One S.D. Innovations \pm 2 S.E.

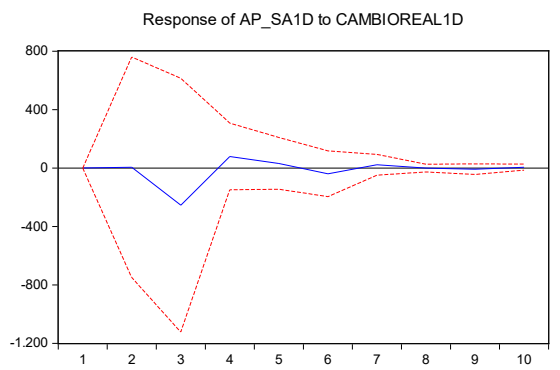

Response to Cholesky One S.D. Innovations \pm 2 S.E. Response of BA_SA1D to CAMBIOREAL1D

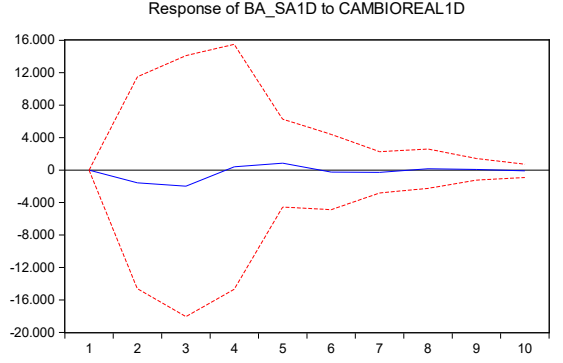

Response to Cholesky One S.D. Innovations \pm 2 S.E.

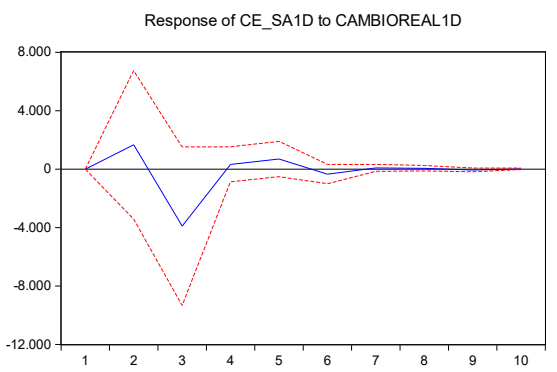

Response to Cholesky One S.D. Innovations \pm 2 S.E. Response of DF_SA1D to CAMBIOREAL1D

Response to Cholesky One S.D. Innovations \pm 2 S.E.

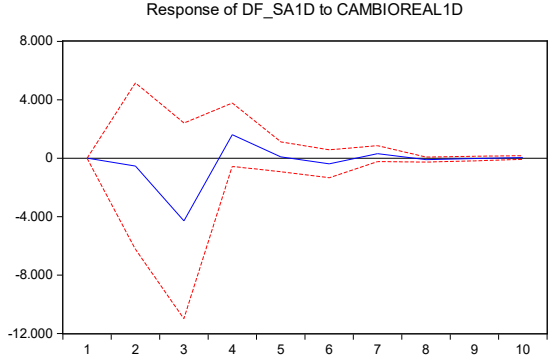

Response of ES_SA1D to CAMBIOREAL1D

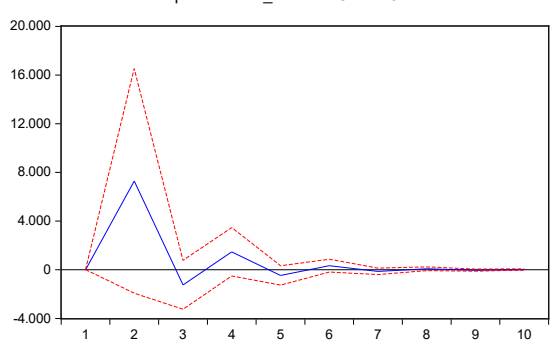


Response to Cholesky One S.D. Innovations \pm 2 S.E. Response of GO_SA1D to CAMBIOREAL1D

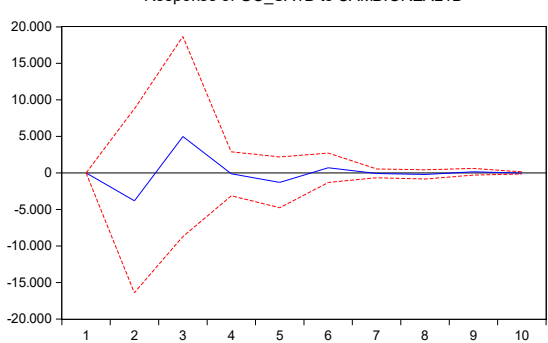

Response to Cholesky One S.D. Innovations \pm 2 S.E. Response of MG_SA1D to CAMBIOREAL1D

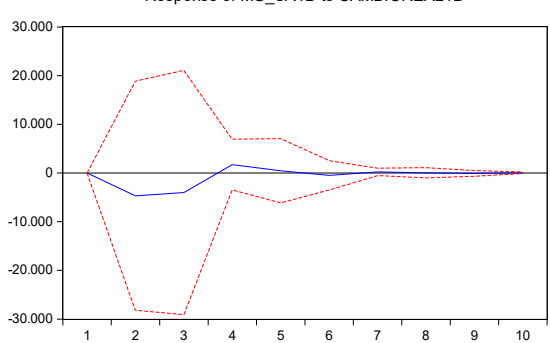

Response to Cholesky One S.D. Innovations \pm 2 S.E. Response of MTSA1D to CAMBIOREAL1D

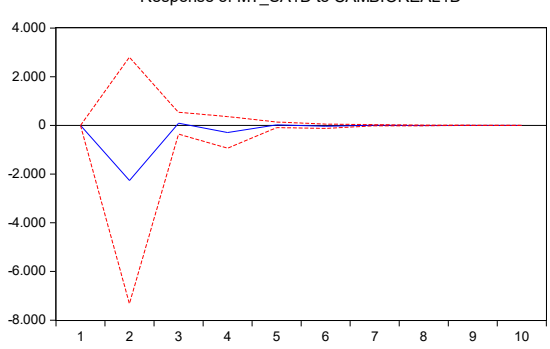

Response to Cholesky One S.D. Innovations \pm 2 S.E. Response of PB_SA1D to CAMBIOREAL1D

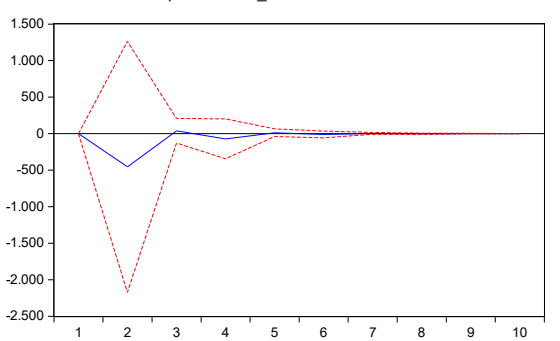

Response to Cholesky One S.D. Innovations \pm 2 S.E. Response of MA SA1D to CAMBIOREAL1D

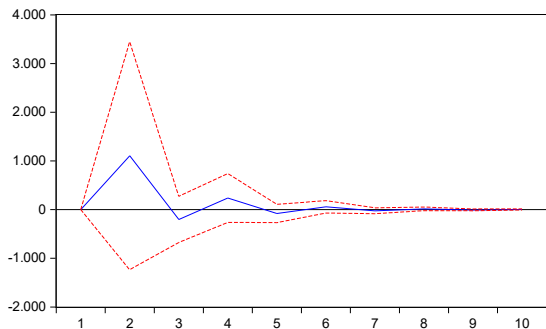

Response to Cholesky One S.D. Innovations \pm 2 S.E. Response of MS_SA1D to CAMBIOREAL1D

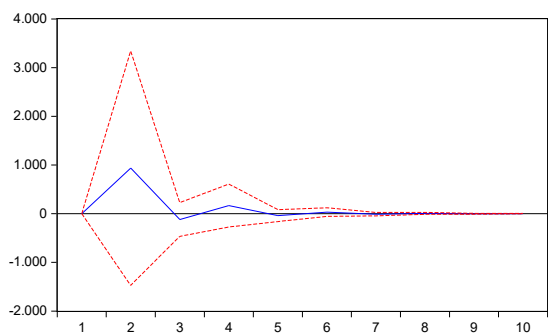

Response to Cholesky One S.D. Innovations \pm 2 S.E. Response of PA SA1D to CAMBIOREAL1D

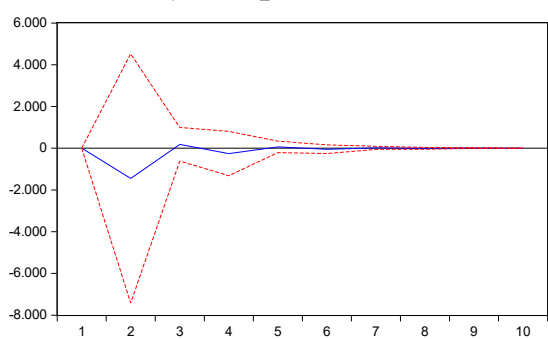

Response to Cholesky One S.D. Innovations \pm 2 S.E. Response of PE_SA1D to CAMBIOREAL1D

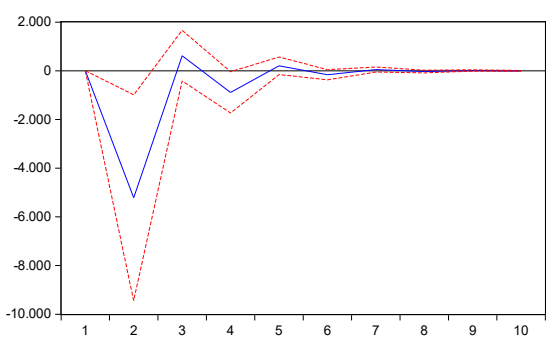


Response to Cholesky One S.D. Innovations \pm 2 S.E.

Response of PI_SA1D to CAMBIOREAL1D

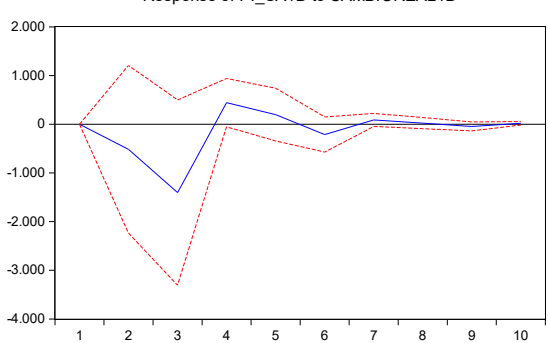

Response to Cholesky One S.D. Innovations \pm 2 S.E. Response of RJ_SA1D to CAMBIOREAL1D

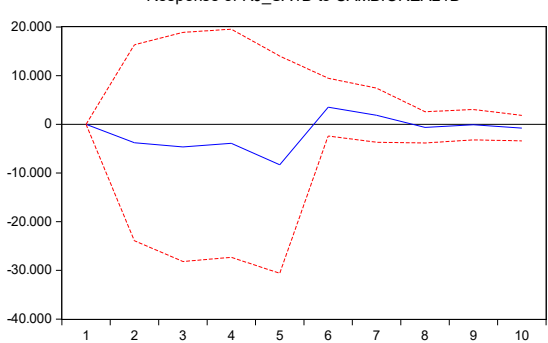

Response to Cholesky One S.D. Innovations \pm 2 S.E. Response of RO SA1D to CAMBIOREAL1D

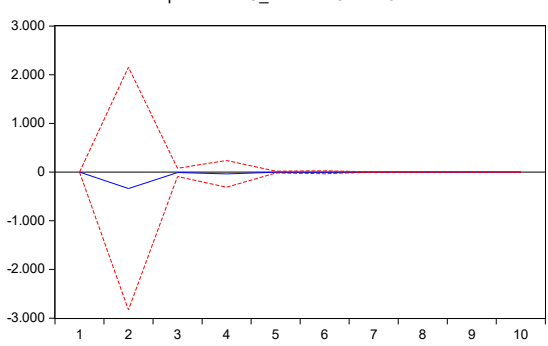

Response to Cholesky One S.D. Innovations \pm 2 S.E. Response of RS_SA1D to CAMBIOREAL1D

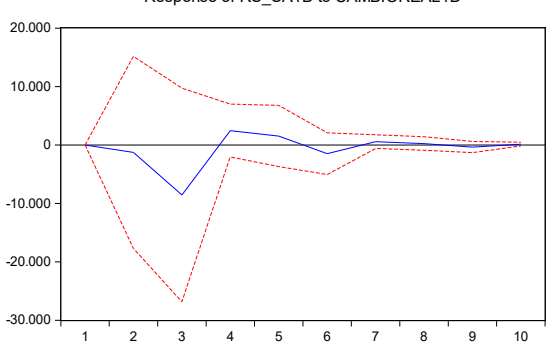

Response to Cholesky One S.D. Innovations \pm 2 S.E. Response of PR_SA1D to CAMBIOREAL1D

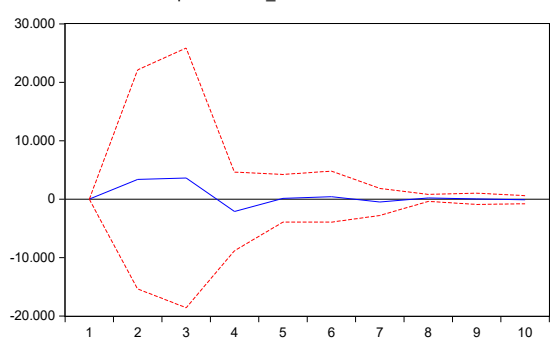

Response to Cholesky One S.D. Innovations \pm 2 S.E. Response of RN_SA1D to CAMBIOREAL1D

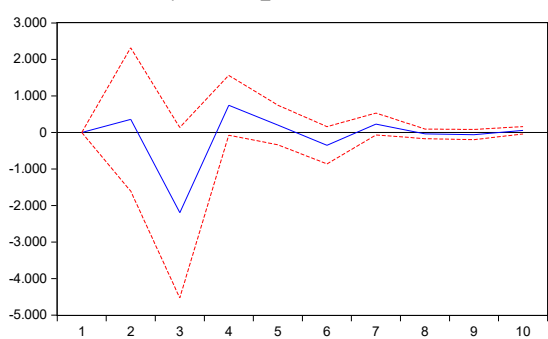

Response to Cholesky One S.D. Innovations \pm 2 S.E. Response of RR SA1D to CAMBIOREAL1D

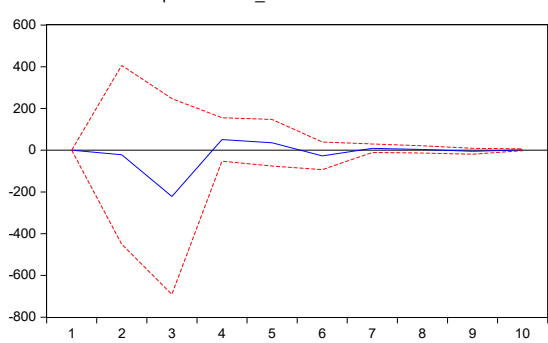

Response to Cholesky One S.D. Innovations \pm 2 S.E. Response of SC SA1D to CAMBIOREAL1D

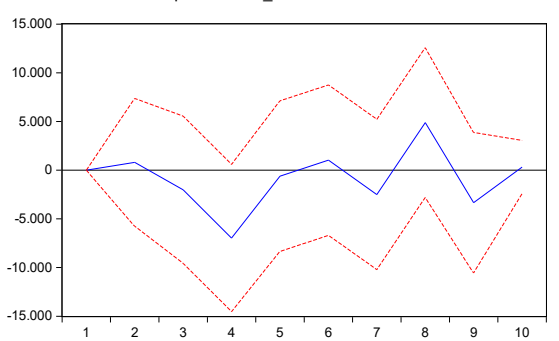


Response to Cholesky One S.D. Innovations \pm 2 S.E. Response of SE_SA1D to CAMBIOREAL1D

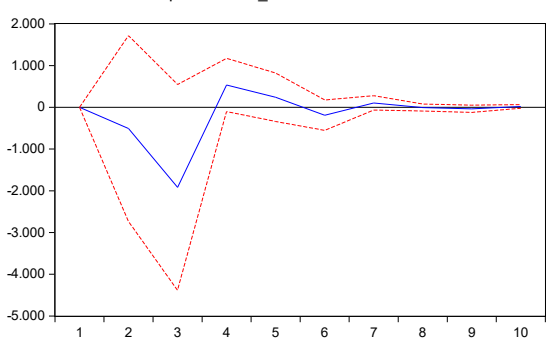

Response to Cholesky One S.D. Innovations \pm 2 S.E.

Response of TO SA1D to CAMBIOREAL1D

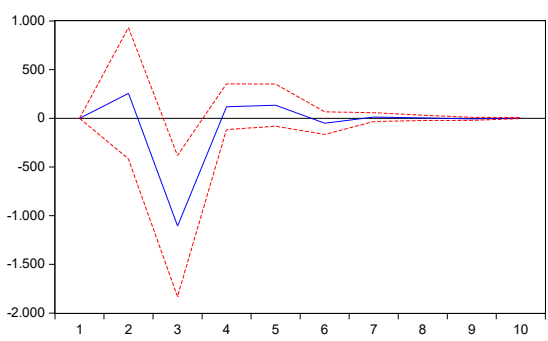

Response to Cholesky One S.D. Innovations \pm 2 S.E.

Response of SP SA1D to CAMBIOREAL1D

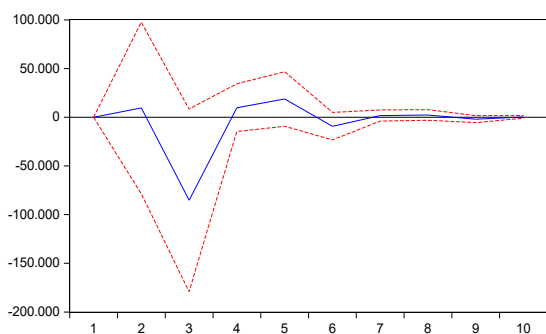

Fonte: Elaboração própria a partir dos dados da pesquisa.

\section{Apêndice 2}

Tabela 7 - Estatísticas Descritivas da Arrecadação de ICMS

\begin{tabular}{|c|c|c|c|c|c|c|c|c|c|c|}
\hline & Média & Mediana & Máximo & Mínimo & $\begin{array}{l}\text { Desvio- } \\
\text { Padráo }\end{array}$ & Skewness $^{1}$ & Kurtosis $^{2}$ & Jarque-Bera $^{3}$ & Probabilidade & Observaçóes \\
\hline $\mathrm{AC}$ & 52.082 & 52106.03 & 108781.9 & 15669.40 & 21576.75 & 0.281473 & 2.149333 & 9.885154 & 0.007136 & 228 \\
\hline AL & 195.640 & 187187.8 & 356816.6 & 116709.1 & 53784.22 & 0.351251 & 1.839394 & 17.48488 & 0.000160 & 228 \\
\hline $\mathbf{A M}$ & 524.669 & 503532.5 & 858888.5 & 276670.6 & 133203.1 & 0.372373 & 2.015260 & 14.48142 & 0.000717 & 228 \\
\hline $\mathbf{A P}$ & 44.559 & 41580.93 & 103476.0 & 15190.55 & 20082.02 & 0.616166 & 2.346615 & 18.48275 & 0.000097 & 228 \\
\hline BA & 1.268 .526 & 1252234. & 2226991. & 875511.9 & 260199.0 & 0.506701 & 2.637385 & 11.00549 & 0.004076 & 228 \\
\hline $\mathrm{CE}$ & 615.507 & 555410.8 & 924774.2 & 407099.7 & 150907.9 & 0.590222 & 1.932403 & 24.06549 & 0.000006 & 228 \\
\hline DF & 478.093 & 482736.6 & 771673.9 & 316907.5 & 103403.7 & 0.287884 & 2.154508 & 9.940465 & 0.006942 & 228 \\
\hline ES & 726.639 & 764764.5 & 1147493. & 301554.3 & 168676.3 & -0.106906 & 1.976738 & 10.38141 & 0.005568 & 228 \\
\hline GO & 818.413 & 724173.9 & 1580198. & 463057.7 & 252131.0 & 0.831429 & 2.647960 & 27.44576 & 0.000001 & 228 \\
\hline MA & 275.744 & 271116.5 & 496494.7 & 115526.1 & 105225.8 & 0.301837 & 1.735750 & 18.64614 & 0.000089 & 228 \\
\hline MG & 2.655 .946 & 2583718 & 4595721. & 1658827. & 595015.2 & 0.364425 & 2.021028 & 14.15128 & 0.000845 & 228 \\
\hline MS & 458.308 & 455927.0 & 727052.3 & 195206.8 & 154170.6 & 0.080856 & 1.634881 & 17.95216 & 0.000126 & 228 \\
\hline MT & 538.763 & 548770.2 & 808978.3 & 257309.2 & 150336.7 & -0.104310 & 1.833744 & 13.33492 & 0.001272 & 228 \\
\hline PA & 512.124 & 494313.3 & 1120613. & 240857.3 & 191242.8 & 0.608800 & 2.510551 & 16.36003 & 0.000280 & 228 \\
\hline PB & 257.581 & 233719.7 & 440082.0 & 163368.9 & 75474.59 & 0.802967 & 2.431472 & 27.57136 & 0.000001 & 228 \\
\hline $\mathrm{PE}$ & 802.417 & 734425.2 & 1233459. & 505876.0 & 230847.6 & 0.518599 & 1.676695 & 26.85571 & 0.000001 & 228 \\
\hline
\end{tabular}




\begin{tabular}{c|c|c|c|c|c|c|c|c|c|c}
\hline & Média & Mediana & Máximo & Mínimo & $\begin{array}{c}\text { Desvio- } \\
\text { Padráo }\end{array}$ & Skewness $^{1}$ & Kurtosis $^{2}$ & Jarque-Bera $^{3}$ & Probabilidade $^{\text {Observaçóes }}$ \\
\hline PI & 173.819 & 160248.3 & 316454.7 & 93624.09 & 63404.55 & 0.518746 & 1.859668 & 22.57909 & 0.000013 & 228 \\
\hline PR & 1.484 .606 & 1419831. & 3228838. & 819434.1 & 376258.9 & 0.879284 & 4.115029 & 41.19056 & 0.000000 & 228 \\
\hline RJ & 2.422 .025 & 2306216. & 3422336. & 1764991. & 381490.8 & 0.549667 & 2.369291 & 15.26014 & 0.000486 & 228 \\
\hline RN & 281.415 & 278950.9 & 428241.6 & 152388.4 & 79118.68 & 0.309173 & 1.857954 & 16.02290 & 0.000332 & 228 \\
\hline RO & 198.883 & 199462.6 & 345214.5 & 85938.75 & 63833.17 & 0.053507 & 1.776164 & 14.33766 & 0.000770 & 228 \\
\hline RR & 36.450 & 33747.24 & 62590.65 & 16147.73 & 12403.63 & 0.281851 & 1.809535 & 16.48220 & 0.000264 & 228 \\
\hline RS & 1.853 .677 & 1.768 .725 & 2.594 .430 & 1.180 .514 & 340.991 & 0.417461 & 2.005942 & 16.00986 & 0.000334 & 228 \\
\hline SC & 1.021 .378 & 932277.0 & 1605476. & 674148.9 & 261878.5 & 0.518757 & 1.890711 & 21.91611 & 0.000017 & 228 \\
\hline SE & 178.542 & 166772.3 & 304378.9 & 86986.88 & 48178.58 & 0.629198 & 2.163285 & 21.69470 & 0.000019 & 228 \\
\hline SP & 9.330 .857 & 8796552. & 14868083 & 5878447. & 1630434. & 0.420994 & 2.141968 & 13.72907 & 0.001044 & 228 \\
\hline TO & 113.236 & 108117.9 & 189018.9 & 50540.40 & 36888.35 & 0.349469 & 2.191448 & 10.85157 & 0.004402 & 228 \\
\hline Câmbio & 135.5584 & 127.6298 & 241.7898 & 91.08562 & 32.41324 & 0.803046 & 2.803947 & 24.87070 & 0.000004 & 228 \\
\hline
\end{tabular}

Fonte: elaboração dos autores com dados da pesquisa.

Obs.: Valores para a média em milhóes de R\$, exceto para SP, RJ, MG, BA, RS, SC e PR que está em bilhôes e para o índice do câmbio.

${ }^{1}$ A obliquidade (Skewness) mede a assimetria das caudas da distribuiçấo. As distribuiçốes assimétricas são aquelas que têm um dos lados da distribuiçáo (abaixo ou acima da média) com mais elementos que o outro, enquanto as distribuiçóes simétricas tem obliquidade igual a zero (existe o mesmo número de sujeitos acima e abaixo da média). Se o valor da obliquidade for maior que zero, isso quer dizer que essa distribuição tem uma lado esquerdo (valores abaixo da média) com mais elementos, se o valor for inferior a zero, entáo a distribuição tem o lado direito (valores acima da média) com mais elementos.

${ }^{2}$ A curtose (Kurtose) mede o grau de achatamento da curva. As distribuições achatadas têm uma maior dispersão de valores pelos extremos da curva e as distribuiçốes altas têm uma maior concentração de valores em torno da média (centro da curva).

${ }^{3} \mathrm{O}$ teste de Jarque-Bera tem como hipótese nula a normalidade. Assim, se o p-valor for menor do que $5 \%$ (ou $10 \%), p<0,05(p<0,10)$, então o autor rejeita a normalidade. Já se $\mathrm{p}>0,05$, aceita-se a normalidade. Na nossa distribuição, podemos notar que todas tem distribuição normal. 